\title{
Discurso referido y puntuación en el Siglo de Oro: el caso de la Olla podrida a la española (1655) de Marcos Fernández
}

Daniel M. Sáez Rivera

\section{CpenEdition}

\section{Journals}

Edición electrónica

URL: https://journals.openedition.org/cher/7174

DOI: $10.4000 /$ cher. 7174

ISSN: 2803-5992

Editor

Presses universitaires de Strasbourg

Edición impresa

Fecha de publicación: 7 julio 2014

Paginación: 235-254

ISBN: 978-2-86820-569-8

ISSN: 1968-035X

\section{Referencia electrónica}

Daniel M. Sáez Rivera, «Discurso referido y puntuación en el Siglo de Oro: el caso de la Olla podrida a la española (1655) de Marcos Fernández», reCHERches [En línea], 12 | 2014, Publicado el 13 diciembre 2021, consultado el 15 diciembre 2021. URL: http://journals.openedition.org/cher/7174 ; DOI: https:// doi.org/10.4000/cher.7174

\section{cc) (1) (-)}

Ce(tte) œuvre est mise à disposition selon les termes de la Licence Creative Commons Attribution Pas d'Utilisation Commerciale - Partage dans les Mêmes Conditions 4.0 International. 


\title{
Discurso referido y puntuación en el Siglo de Oro: el caso de la Olla podrida a la española (1655) de Marcos Fernández ${ }^{1}$
}

\author{
Daniel M. Sáez Rivera \\ Universidad Complutense de Madrid
}

\section{Presentación de la Olla podrida a la española}

La Olla podrida a la Española, Compuesta i saçonada en la Description de Munster en Vesfalia con salsa Sarracena i Africana. Por ser efta ciudad mas a proposito que otra para Olla podrida, con la verdadera Ortografia âsta âora inorada (Amberes [=Amsterdam]: Felipe van Eyck, 1655) es la obra más conocida de Marcos Fernández, maestro de lenguas itinerante que, de origen probablemente salmantino, recorrió Europa (Francia, Países Bajos, Alemania - así Münster, la ciudad retratada en la Olla -, y Holanda) enseñando español a la nobleza europea, así como a la burguesía holandesa, incluso judía y sefardíi . El librito es por un lado un tratado de ortografía inductiva que presenta una peculiar ortografía idiosincrásica (cf. Sáez Rivera 2005, 2009), y por el otro una sátira menipea ${ }^{3}$, por características como la configuración carnavalesca (polifonía textual y parodia, incluso de textos gramaticales), la alternancia de prosa-verso y serio-cómico, la libertad temática y la crítica a la actualidad histórica y al pensamiento oficial. Así, don Marcos realiza en forma de miscelánea barroca un retrato de primera mano no muy halagüeño

1 Este trabajo se encuadra en el proyecto nacional español Programes 4: «Procesos de gramaticalización en la historia del español (IV): gramaticalización y textualización», referencia FFI2012-31427.

2 No me detengo en la vida y el resto de la obra de Marcos Fernández, para lo cual remito a Sáez Rivera (2010: 173-176), en Recherches 5. Sobre la Olla podrida como texto literario, destaca el trabajo de Vaíllo (2006).

3 Según la definen Kristeva (1969: 103-107) y Valdés (2006, 2008). 
de la ciudad de Münster, de sus edificios y tipos humanos (con especial detenimiento en las mujeres y en los médicos, boticarios y barberos), así como recuerda los hechos históricos más recientes allí acaecidos, como las conversaciones de Paz de Münster (1643-1648), que presenta como ridículas, y la revolución de los anabaptistas liderada por Juan de Leide, que condena. Para rematar su obra termina con una fábula caballaresco-burlesca contra las disensiones entre las naciones cristianas frente al Turco y a favor de la recuperación de los valores nobiliarios-caballerescos, y con una serie de poesías religioso-morales plagiadas en su mayoría de Gregorio Silvestre. La obra está además llena de ecos picarescos, quevedescos y cervantinos, de entre los que destaca la aparición de Toncho Panza, nieto de Sancho Panza en la mencionada fábula o «Capitulo, i esplicacion de la palabra, Idalgo, $o$ Idalga» (p. 232-282) ${ }^{4}$.

\section{Propósito de estudio:}

\section{puntuación y discurso referido en la Olla podrida a la española (1655)}

De todos los hechos polifónicos de la obra, en este trabajo nos centraremos en la configuración ortográfica y morfosintáctica del discurso referido en la Olla podrida a partir del impreso original cuyas páginas citaremos directamente entre corchetes ${ }^{5}$, con solo algunos comentarios sobre otros elementos polifónicos. Con ello introducimos la novedad de compatibilizar los estudios de puntuación en el Siglo de Oro (Catach 1996; Díez Fernández 2008; Santiago 1998; Sebastián Mediavilla 2000, 2002, 2007, 2008, 2010), con los estudios morfosintácticos y de punto de vista discursivo sobre el Discurso Referido (DR) en español, especialmente diacrónicos (Girón Alconchel 1985, 1986, 1989, 2000, 2002, 2006, 2008; Méndez 2009), los cuales suelen estar normalmente disociados.

\section{Esquema general discurso referido}

Ante la existencia de diversos modelos de análisis del discurso referido en español, para los propósitos que en este estudio nos hemos planteado, vamos

4 Capítulo editado parcialmente por Arellano (2005) y al completo por Sáez Rivera (2008b).

5 El ejemplar original que hemos utilizado para el análisis y de donde extraemos los ejemplos citados es el guardado en Madrid, en la Biblioteca Nacional de España, con la signatura R-7548, accesible fácilmente en la red a través de la Biblioteca Digital Hispánica (http://bdh.bne.es/bnesearch/), y que ya utilizamos como texto base (Greg 1950-1951) para nuestra edición parcial de la Olla podrida (Sáez Rivera 2008b). Se trata de un volumen en octavo compuesto por 6 hojas sin foliar y 324 páginas. 
a prescindir de los estudios más de corte gramatical, autolimitados desde un punto discursivo, como los de Maldonado (1991, 1999) ${ }^{6}$, y en cambio nos vamos a inclinar por modelos discursivos aplicables o ya aplicados a discursos actuales y pasados, como son los diversos publicados por Girón Alconchel (en particular 2000, 2002, 2006, 2008).

De esta manera, los elementos del Discurso Referido (a partir de ahora, DR) son, según Girón Alconchel (2006: 399; 2008: 177), estos:

1) un enunciador distinto del locutor del texto, 2) una situación comunicativa distinta de la que el locutor establece con su interlocutor, 3) un esquema sintáctico que marca la conexión del discurso reproducido y el discurso que reproduce (el marco reproductor) y 4) un comentario del marco reproductor sobre el discurso reproducido.

Asimismo, el esquema general que adopta la forma de discurso reproducido sería el siguiente (Girón Alconchel 2006: 399; Girón Alconchel 2008: 177):

Marco reproductor $\mathrm{X}$ dijo a $\mathrm{Y}$
Discurso reproducido

Z

El marco reproductor se reconoce por poseer las siguientes características: (Girón Alconchel 2002: 626-627):

1. Señales demarcativas: el enunciador o personaje $\mathrm{e}^{7}$, un verbo de lengua que marca un acto de habla, pensamiento o percepción, y una señal de relación sintáctico-semántica (yuxtaposición-subordinación en diferentes grados, según la presencia de diferentes tipos de puntuación y conjunciones, yuxtaposición y parataxis para el discurso directo, subordinación para el discurso indirecto e hipotaxis para el discurso mixto en sus diferentes tipos - discurso indirecto subordinado o ligado, discurso indirecto libre o mimético -, transición entre el directo y el indirecto, y máxima integración para el discurso narrado en el que el discurso reproducido se compacta en un verbo y/o un sustantivo de comunicación)

2. Indicios externos de reproducción: según las formas léxicas o gramaticales que describen actitud comunicativa de los personajes (actos de habla, elementos no verbales...).

6 Por ejemplo, Maldonado (1999: 3554) señala que, aunque el estudio del DD y del DI se puede enfocar desde el punto de vista de la organización textual en un enfoque pragmático en forma de reproducción del discurso, o como resultado de dicha organización en forma de discurso reproducido, la autora se centra más bien en el segundo enfoque.

7 Frente al locutor que emite el texto. 
Por su parte el discurso reproducido se caracteriza por estos elementos (Girón Alconchel 2002: 626-627):

1. Rasgos distintivos: formas personales, deícticos y formas modotemporales del verbo, con dos centros deícticos independientes en el discurso directo y transposición a uno solo en el indirecto (con transiciones de distinto grado en el mixto), así como modalidad de la enunciación-entonación, con pausa y dos entonaciones en el discurso directo, y una sola curva melódica en el indirecto (y de nuevo diferentes instancias transicionales)

2. Indicios internos de reproducción: vocativos, exclamaciones, elementos fáticos, marcadores discursivos, modalizadores (adverbios, perífrasis), variedades internas de la lengua reproducida (diatópicas, diastráticas, diafásicas, diacrónicas...) son típicos del discurso directo, y si se manifiestan en el indirecto inducen el discurso indirecto libre.

Todos estos elementos configuran diferente tipos de DR que se pueden conceptualizar como una «cadena de gramaticalización», según el siguiente esquema de Girón Alconchel (2006: 404; 2008: 177):

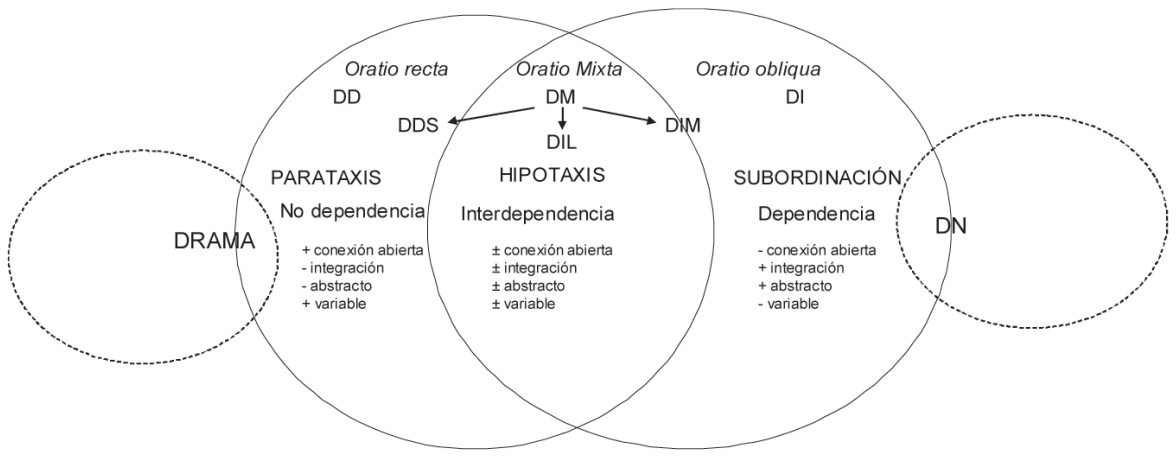

\section{Normas de puntuación de Fernández}

Ya hemos comentado que Marcos Fernández emplea en general una ortografía peculiar o propia, que hemos llamado idiosincrásica, por lo que posee una gran consciencia gráfica. Así explicita unas normas ortográficas, incluidas las de puntuación, en la Instruction espagnole accentuée (Colonia: Andrea Bingio, 1647), mientras que ofrece la ortografía -y por tanto la puntuación- de la Olla podrida a la española (1655) como ejemplar.

Para analizar su obra conviene adoptar el modelo de análisis para textos gramaticales y paragramaticales de Girón Alconchel (1996) según el cual se distingue entre usos descritos, usos prescritos y usos escritos, esto es, entre 
lo que un gramático dice que se suele decir (uso descrito), dice que se debe decir (uso prescrito) y lo que efectivamente dice (uso escrito), no siempre de forma concordante con lo que prescribe (uso prescrito) y con frecuencia documentando usos de los que ni siquiera es consciente o no llega o acierta a describir (uso descrito). Respecto a la puntuación, hay que considerar además el problema de que normal o frecuentemente se introducían en el proceso de producción del libro impreso por copistas de la copia en limpio, cajistas o impresores, a no ser que el autor hubiera tenido especial cuidado de vigilar la puntuación que se insertaba, lo cual no solía ser el caso (las excepciones son contadas, como Mateo Alemán, que llegó a escribir «De manera, que no sólo se llamará ortografía, la del bien escrevir, mas aun la de la congrua puntuación» en su Ortografía castellana (México, 1609, págs. 32-33), apud Sebastián Mediavilla 2007: 50). En cuanto a Marcos Fernández, aunque no tenemos testimonio directo de que haya sido así, a juzgar por su monomanía ortográfica sí debió de controlar la puntuación de sus impresos.

Se puede ver una primera interacción o posibilidad de análisis según los distintos usos en las normas concretas para puntuar que formula Fernández en su gramática, la Instruction espagnole accentuée (1647: 151):

De los Pùntos pàra Separár las pàrtes, i ôraciònes, que són siète, i se llàman ô nombran, asi, Coma.

Pùnto. Coma, i pùnto, dos pùntos, l'interrogación, perèntesis [sic], esclamación, Coma es ésta (,) la quàl se pòne quàndo se pàrte la ôración en mùchas pàrtes, còmo compré ùn cavàllo, que me costó tànto.

El segùndo es còma abàxo, i pùnto arrìba, còmo èsta (;) se pòne quando la ôración se divide en dós ô mas còsas, i en ablàndo de càda ùna en su particular al fin se pòne, còmo, fui â Munster, i còmpre [sic] ûna càsa; salièndo de allá, lo bòlvi $[$ sic $]$ a vendér.

El tercèro, son dos pùntos, còmo èstos (:) que se pònen quàndo algùno quière cón algúna autoridád, confirmár lo que â dìcho, còmo dìgo èsto âsi: que es buèno callár, pàra sabèr âblar.

El quàrto es un pùnto còmo èste (.) que concluye la oración, ô discùrso, còmo abacé [i.e. acabé] de comér. ensillé mi cavàllo.

El quinto se llàma interrogación que se pòne quàndo se pregùnta còmo îciste esto? està es su forma i ê chùra?

El sèsto, se llama parèntesis, se pòne quàndo se interpòne alguna cosa en la oración, cómo no fuèra muèrto (decì mi amìgo) si el enfèrmo tomàra la pùrga, veis alli su figùra.

El sètimo se pòne quàndo âi esclamación, còmo, es mùerto mi compadre ô quàn miserables que darán sus îjos (!) ves aquí su â churasa [i.e. êchura] 
En estas normas, se explicita como uso prescrito el apartado tercero, en el que se indica que los dos puntos sirven para introducir el discurso de una autoridad, una de las formas de DR en forma de discurso directo: «El tercèro, son dos pùntos, còmo èstos (:) que se pònen quàndo algùno quière cón algúna autoridád, confirmár lo que â dìcho, còmo dìgo èsto âsi: que es buèno callár, pàra sabèr âblar». Ahora bien, los usos escritos en este mismo apartado también nos indican otras posibilidades de puntuación de DR, como en el segundo apartado, en el que la alteridad polifónica de un ejemplo se introduce mediante coma después del comparativo como: «El segùndo es còma abàxo, i pùnto arriba, còmo èsta (;) se pòne quando la ôración se divide en dós ô mas còsas, i en ablàndo de càda ùna en su particular al fin se pòne, còmo $_{2}$ fui â Munster, i còmpre [sic] ûna càsa; salièndo de allá, lo bòlvi [sic] a vendér». Otra posibilidad de puntuación del DR es el paréntesis, como se puede deducir como forma de uso escrito en el ejemplo que ilustra el sexto apartado: «El sèsto, se llama parèntesis, se pòne quàndo se interpòne alguna cosa en la oración, cómo no fuèra muèrto (decìa mi amìgo) si el enfèrmo tomàra la pùrga, veis alli su figùra». Y todavía hay otro uso escrito que ilustra las posibilidades de puntuación del DR, que es la ausencia de puntuación, como precisamente en el apartado sexto (y casi en el resto de la misma página), en el que tras el comparativo como se introduce directamente el ejemplo.

La delimitación del discurso directo mediante dos puntos, coma, paréntesis o ausencia de puntuación se documentará también como uso escrito en la Olla podrida (prueba del control y de la consciencia al respecto mostrada por Fernández), pero también otras posibilidades que señalaremos a continuación.

\section{Usos escritos en la Olla podrida}

Los usos escritos de puntuación en la Olla podrida a la española (1655) son un poco particulares, en el sentido de que, según declaración del autor, se deben tomar como ejemplares, por lo que probablemente su inserción (y la corrección de pruebas, como sabemos que sí ocurrió con la Instruction espagnoles accentuée, cf. Sáez Rivera 2008a: 898) haya sido controlada por Fernández.

\section{Discurso directo $(D D)$ en la Olla podrida}

La mayoría de ejemplos de discurso directo están introducidos mediante dos puntos, lo que podemos notar como «: DD», con lo que se muestra cómo la puntuación más versátil al respecto, pues introduce parlamentos de 
diversa extensión desde corta a larga (como ocurre en el Quijote, cf. Sebastián Mediavilla 2008), según se puede ver en el ejemplo (1)8 (en el que además localizamos la referencia cervantina a «Dulcinea del Toboso») $)^{9}$. Aquí el DD tiene cierta extensión, frente al mucho más corto de (2), donde además observamos polifonía idiomática porque se introduce un parlamento en el dialecto germánico de Münster, ya en el original en cursiva:

(1) Acabó mi dicipulo su relacion, i yo ledixe: cierto, Señor, que avia conocido en vos, (viendo vuestra cara palida, contemplativa, ôjos encobados,corto de vista,) amores de alguna [p. 121] Dulcinea del Toboso imbisible; mas los vuestros fueron reales, que tomarades vos el pago, aun que fuera en sus quartos: la fortuna os avia dado comision, i ocasion, para acuñar moneda; Cupido los materiales, i fragua encendida, pasose, i por ser valva, no teneis por donde asirla, ciego aveis salido esta batalla, i mas, si uvierades perdido la vista, por donde los gigantes miran, [p. 122]

(2) lo primero que me dixo, aquella cara de Leon de piedra, remedio contra lujuria: estraque minier [p. 156]

En cambio, la puntuación con coma en forma de «, DD» parece reservarse para los parlamentos cortos, de nuevo como en las ediciones del Quijote analizadas por (Sebastián Mediavilla 2008). Un buen ejemplo es (3), que muestra de nuevo la polifonía idiomática germánica, esta vez sin cursiva en el original:

(3) le pregunte en prosa Española por el barbero, como si le âblara griego, por que me dixo, estraque, estraque, minier [p. 149]

Las citas largas de DD se señalan normalmente con punto, en forma de DD, de nuevo en concordancia con lo habitual en el Quijote (Sebastián Mediavilla 2008), como ocurre en los largos turnos de habla de las conversaciones de paz representadas en el capítulo I, así (4):

(4) El primero que se manifesto, en este tablado, fue el Nuncio de su Santidad ${ }^{10}$, diciendo asi. La divina providencia dispuso i ordeno, que las gentes (antiguamente) con maduro consejo îciesen siete eletores, en todo el Cristianismo, los quales fuesen de diferentes religiones, para que elegiesen Emperador, que fuese caudillo, i general contra el Turco, enemigo declarado

8 Según la práctica de Girón Alconchel (passim), con ciertas modificaciones, señalo con negrita el marco reproductor, incluido el signo de puntuación que marca la transición al enunciado reproducido, que se delimita con subrayado, en forma de DI pero también DD (el profesor Girón no subraya el DD), mientras que el DIL/DIM se señala con cursiva.

9 Anoto siempre las erratas a pie de página, primero la corrección y luego el original marcado con impr. (= impreso), así como también hago algunas aclaraciones adicionales.

10 Fabio Chiggi (convertido en Papa en 1655, con el nombre de Alejandro VII). 
de todo el Cristianismo, los quales Emperadores [p. 8] por muchos siglos le ân impunado, i escurecido sus medias lunas, con notables vitorias, por mar i tierra. con ellas el aguila Imperial â aumentado sus plumas i lustrandolas, i renovandolas, con particulares progresos, âciendose emperatriz de todos quatro elementos, eclibsando las armas enemigas, con diferente eclibse, que el que eclibso, i escurecio, a esta ciudad ayier a 12. de Agosto. Juntamènte, a esta comision militar, se le coadjudicó la de juez temporal, para exercer justicia, en todo el Cristianismo (i los que esto olvidan con malicia,es que ellos quieren juzgar contra justicia) nombrando Cancillerias en diferentes Provincias, con jueces de virtud i letras, i Presidente imperial, i estos de diferentes religio[-] [p. 9] nes, para quitar toda sospecha. Soi Venido aqui de la parte de su santidad, acompañandome el excelentisimo Sr. Plenipotenciario de la Republica de Venecia, para mediar entre V. exs. a uyentando la dilacion al despacho, i concordia, con brevedad: todos unidos vamos contra el Turco, que en Candia oprime con rigor a nuestros êrmanos, â emitacion del sin segundo Carlos quinto, que âciendo paces gloriosas en Italia, tuvo por mayor gloria ver las espaldas al comun enemigo, sinque osase aguardar en todo el Imperio, temiendo el rebano de sus turbantes, i medias lunas, tal se lo prometia, la tiçona ô colada de aquel braço imbencible; abracemos la paz que Jesu Cristo nos dexo, ruibarbo con que se purgan las raço- [p. 10] nes de estado de Maxabelo, limpios los reinos, i republicas,se âra un concilio,tan necesario quanto deseado de todos,Dios loquiera. [p.11]

Es particularidad de Fernández, o de su impresor, introducir el DD mediante punto y coma, como «; DD», como en (5). El ejemplo registra además una explicación irónica del habla de los judíos como nota polifónica adicional:

(5) juzgué que el caso no pasaria sin alboro- [p. 130] to, despues de otros muchos, meti el basto, estando seguro que ninguno de lôs dos meteria la espadilla, diciendo; la colera sin fundamento â cegado a V. Ms. por que en esta tierra somos todos unos, aqui no ai mayores todos somos iguales,porque los Señores desta Republica tienen establecido el amor reciproco, la caridad mutual, de tal manera, que para mostrar este amor nos llamamos primos, compadres, i los viejos a los moços sobrinos, i tambien a los viejos tios V. Md. Señor D. como recien venido, no tiene obligacion a saber las costumbres, mas advertido, si, fuera desto âga V.Md. cuenta que estamos en guinea,adonde todos se llaman primos, que no somos tan blancos, que no parezcamos [p. 131] tales primos; Jurar por el Dios de Abrahan i Jacob no es jurar por Dioses diferentes,por que es solo un Dios, a quien todos adoramos, i Vmd. tambien, como Cristiano viejo, i cavallero, fuera de que Abrahan fue el primer Profeta, i el primer grande; [p. 131]

No son pocos tampoco los casos de DD sin puntuación, de modo que debemos depender de los indicios del marco reproductor (verbos de 
lengua, deícticos como «así», etc.) para delimitar correctamente el DD. Las muestras que aducimos a continuación incluyen además otros indicios de reproducción como la polifonía idiomática (6), parcialmente marcada con cursiva, y como las variedades del español, en este caso el sayagués practicado por Toncho Panza, con empleo del rotacismo o permutación de $l$ por $r(7)$ :

(6): no ûvo bien raspadome el xabon, i desocupadome los labios, quando pregunte por el barbero, pensando [que] siempre se estaria lavando las manos; ella medixo ya minier [p. 157]

(7) Toncho respondió a mi me toca como a escudero el âbrar, i responder,i preguntar;como aveis de âllar papel,ô carta en poder de mis camaradas, pués asi como nos vimos rodeados de tantos cavalleros andantes, todos nos çullamos, como lo podeis oler, i aun ver, i pardiobre cada uno se enxabonó con el papel que traia, ârto mal. [p. 262]

Un caso especial lo constituye el marco reproductor enunciativo presentado como un inciso en mitad del DD, interrumpiéndolo, con las posibilidades de puntuación entre comas o entre paréntesis, sin puntuación (total o parcialmente) y puntuación varia, en todo caso insuficiente (solo una coma, o dos puntos, etc.). Ejemplo de puntuación entre comas y entre paréntesis se puede observar en (8a), donde se produce además una lograda mímesis de la oralidad (polifonía oral) por interrupción dialogística con robo de turno, que señalamos con puntos suspensivos en nuestra edición moderna (Sáez Rivera 2008b: 295), que reproducimos en (8b) para facilitar la comprensión del pasaje.

(8a) vayan se de aqui, que me enfadan, dixo el Señor Alferez, que si estuviera aqui mi criado,que tiene mi espadin, les diera, (tampresto dixo uno) los buenos dias Señor Alferez; no lo difiera por falta de espada, que sin duda àcompañó a la vandera, tome la mia; [p. 243]

(8b) -Váyanse de aquí, que me enfadan -dixo el Señor Alférez-, que si estuviera aquí mi criado, que tiene mi espadín, les diera...

Tan presto dixo uno:

-... los buenos días, Señor Alférez, no lo difiera por falta de espada, que sin duda àcompañón ${ }^{11}$ a la vandera, tome la mía.

Ejemplos de puntuación insuficiente, con el inciso enunciativo solamente marcado al final, mediante dos puntos (9) o coma (10), son los siguientes:

(9) Ablad en ora buena dixo el Rei: yo no soi espiga, ni de trigo, ni de centeno, ni aun de cevada, que si eso fuera, ya mi rucio me uviera comido,

11 Así en el texto impreso original, con dos acentos, uno grave y otro agudo. 
pero soi Toncho Pança, îjo de Sancho Pança,escudero terrible, del mas terrible cavallero, llamado Don Quijote de la Mancha, desfacedor de tuertos, i de- [p. 254] rechos; cuyos fechos, i façanas suenan por todo el mundo, tanto como la campana de mi lugar; [p. 255]

(10) mas por vida de mi Señora madre dixo un criado, que somos naturales de Herez i yo soi higo de una muher onrada que vivia alcahalgadero de las moças quando van por agua, alli me hahardava taña tia, calentandose a la candela, âsta que yo llegava [p. 43]

Cercano o fusionable con el DR es el uso metalingüístico (se utiliza la lengua para hablar de la lengua, para «citar» elementos de ella), que hoy marcamos con cursiva o con comillas, y que aquí aparece entre comas en (11) y (12), origen así mismo del señalamiento metalingüístico mediante comillas:

(11) La segunda muralla sirve de atril i apoyo a cantidad de casas, según lo que se pnede ${ }^{12}$ juzgar por ellas, forma una, $\hat{o}_{2}$ [p. 4]

(12) Tam presto, que oyieron los embaxadores abentureros esta palabra, dama, luego conocieron, que a ellos venia la pelota, [p. 26]

Sí se emplea en la Olla podrida el recurso tipográfico de la cursiva para señalar un tipo de polifonía textual, la aparición de otras lenguas, aquí el latín y el dialecto wesfálico, aunque en el impreso no se procede de forma regular: unas veces se inserta cursiva y otras no, incluso con una misma palabra, como ocurre con «ergo» en el ejemplo (13) pero «ergo» en (14), o con palabras distintas, como «quatenus» frente a «substantia» $\mathrm{y}$ «forma» en (14):

(13) dixo con gran alegria: mas âllé de lo que buscava; a mi ciencia nada se puede esconder; ergo ergo; los dos machos que àn nacido, el uno es raciocinante, i el otro no: [p. 258]

(14) respondiome con mucha severidad: confesare mi Señor, i tengo confesado en muchas ocasiones, que no solamente estuve una vez en la celebre Universidad de Duai, pero bien veinte veces, i la que menos fue mas de tres oras; no perdiendo la asistencia del mercado; no mal esquilmo, para quien lo en- [p. 183] tiende, por los granos de trigo, icevada, centeno, i avena, que se mezclan con la basura, que acri vandola, âgo un pan como unas nueces de todo trigo;pues se aun mas de lo que ê dicho; el asperges, i el aleluya, i el credo repiqueteado, i levanto los fuelles, al organo, que sin mi no sonara nada, ergo; i el quatenus; substantia; i tambien forma: [p. 184]

Por último en este apartado, quería presentar algunas dudas sobre la delimitación del DD en el texto original o su posible interpretación como

12 puede ] pnede impr. 
tal o como discurso indirecto (DI). Las dudas de los editores modernos acerca del comienzo o fin de diálogos y parlamentos en los impresos del Siglo de Oro son frecuentes, tanto como las discusiones sobre puntuación en ediciones del Siglo de Oro (Díez Fernández 2008: 384), sobre todo precisamente acerca de la puntuación y delimitación de parlamentos, sobre la que suele haber divergencias entre ediciones (así El Criticón, cf. Sánchez Laílla 2001). Un ejemplo es el del texto original de (14a), en el que dentro de lo señalado en negrita realicé una delimitación de enunciadores en Sáez Rivera (2008b: 301), recogida en (14b), que ahora creo que es incorrecta, con lo que he decidido corregir la puntuación ofrecida anteriormente por la que propongo en (14c):

(14a) El Señor sacristan respondió: no es la miel para la boca del asno, este es badrigio de Praton, ô de Olofernes su êrmano: lo mas que yo êvisto Señora Pança,es que el Se- [p. 258] ñor Governador de la isla Varataria vive; digo el Señor Sancho Pança, el qual gobierno los Señores Duques le ân dado ereditario, para todos sus erederos, beve, i come a dos carrillos, porque el Dotor recio se murio, ergo, ergo. no es el muerto; porque si lo fuera, se ûviera comido (por lo menos) tres cabrillas; yo âllo todas siete en el cielo, ergo, ergo: mas que el gran cavallero Don Quijote va siempre desfaciendo agravios, i tuertos, pero sin escudero; por estar Sancho a pie quedo en su gobierno: aviendo los dos imbiado a un Malandrin a esta tierra; por el eredero de Sancho Pança, i que lleve rucio, por que el suyo esta mui viejo: el malandrin por ser pretensor, como yo deste curato, buelve diciendo: [p. 259] que no avia eredero. Criad presto a los dos, porque infariblemente, solo el es el mayor,aquien le toca la erencia. Dixo, mi Señora madre Pança: seguro que el es el mayor asno; asi lo dice el Metropolitano, respondio el sacristan. [p. 260] (14b) »El señor sacristán respondió ${ }^{13}$ :

"-No es la miel para la boca del asno, este es badrigio de Pratón, ô de Olofernes su êrmano: lo más que yo ê visto, señora Pança, es que el Se[p. 258] ñor Governador de la isla Varataria vive, digo el Señor Sancho Pança, el qual gobierno los Señores Duques le ân dado ereditario para todos sus erederos; beve, i come a dos carrillos, porque el Dotor recio se murió, ergo, ergo, no es él muerto, porque si lo fuera, se ûviera comido (por lo menos) tres cabrillas; yo âllo todas siete en el cielo, ergo, ergo, mas que el gran cavallero Don Quijote va siempre desfaciendo agravios, i tuertos, pero sin escudero, por estar Sancho a pie quedo en su gobierno, aviendo los dos imbiado a un Malandrín a esta tierra por el eredero de Sancho Pança, i que lleve rucio, porque el suyo está mui viejo. El malandrín por ser pretensor, como yo, d'este curato, buelve diciendo [p. 259] que no avía eredero.

13 Tilde ya en el impreso original. 
»-Criad presto a los dos, porque infariblemente, solo él es el mayor, a quien le toca la erencia ${ }^{14}$-dixo mi Señora madre Pança.

»-Seguro que él es el mayor asno, así lo dice el Metropolitano -respondió el sacristán.

(14c) »-No es la miel para la boca del asno, [...] Criad presto a los dos, porque infariblemente, solo él es el mayor, a quien le toca la erencia.

"Dixo mi Señora madre Pança:

»-Seguro que él es el mayor asno.

»-Así lo dice el Metropolitano -respondió el sacristán.

Este ejemplo destaca además porque se produce una mise en abyme típicamente barroca, por la cual torna metadiscurso la metaficción por la que unas narraciones se insertan unas dentro de otras, como en el Quijote ${ }^{15}$ y aquí dentro del marco general de la Olla podrida con la repentina narración del "Capitulo, i esplicacion de la palabra Idalgo, o Idalga», al final de la cual se reenlaza con la argumentación general del libro. En medio de este capítulo un personaje, Toncho Panza, cuenta en un diálogo su nacimiento, narración dentro de la cual también se introduce un diálogo. Para plasmar tal complejidad de diálogos insertados dentro de un diálogo decidí en (14b) prolongar el parlamento de Toncho con comillas de seguir, después de las cuales he abierto rayas de diálogo para los parlamentos que introduce el bueno de Toncho en su relato.

Otro problema lo ofrece la frecuente supresión del que completivo en la sintaxis del Siglo de Oro (Herrero 2005: 96-97), hoy prácticamente limitada a verbos de ruego y a un contexto formal y jurídico-administrativo (con ejemplos del tipo Rogamos se presente durante la próxima semana en la Delegación de Hacienda más próxima a su casa). Tal supresión hace que realmente ejemplos como (15) o (16) puedan ser interpretados como casos de DI o DIL (discurso indirecto libre, marcado aquí con cursiva) con supresión de que (que introduzco entre corchetes) o DD. Así, (17a) se puede puntuar modernamente sin comillas, interpretado como DI sin que, o con ellas, tomado como DD, conforme se puede observar en (17b).

(15) quando saliendo a la calle a seis casas, vi una quemada, a donde yo sabia [que] vivia una deidad [p. 120]

(16) por tanto suplica a vuesa Mag. [que] de orden, para que su gente les dexe pasar, [p. 252]

14 erencia] ereneia impr.

15 La bibliografía sobre la metaficción en el Barroco, y más concretamente en el Quijote, es copiosa, por no decir inabarcable. Cito aquí solo algunas muestras recientes: Arboleda (2011), López Navia (2006), Pagnoni Berns (2011), y la bibliografía ahí citada. 
(17a) se dice dichoso es el ijo, que tiene a su padre en el infierno [p. 86]

(17b) se dice [que] dichoso es el ijo, que tiene a su padre en el infierno / se dice: «dichoso es el ijo que tiene a su padre en el infierno»

\section{Discurso indirecto en la Olla podrida}

En relación inversamente proporcional a la puntuación más frecuente para el DD, la mayoría de ejemplos de discurso indirecto aparece puntuada con coma, en forma de ", DI» (una muestra en 18), aunque también hay ejemplos de DI introducido con dos puntos, según el esquema «: DI» (como en 19):

(18) lo qual me de claró la enima, i confusion que tenia;pero sin esperança pues me añadieron, que entoda a quella semana, se casava la ija, [p. 121]

(19) La buena figura del celebro ar- [p. 88] guye Galeno (lib. artis medic. c. II.) considerando por de fueta [sic], la forma, i compostura de la cabeça: la qual dice: que seria tal qual conviene, tomando una bola de cera perfetamente redonda i apretandola un poco por los lados quedaria desta manera la frente $\mathrm{i}$ el cogote con un poco de giba, de donde se sigue, que tener el ômbre la frente muí llana i el cogote remachado que no tiene su celebro la figura que pide, el ingenio, i âbilidad. [p. 89]

De nuevo como particularidad de la Olla podrida, existe algún ejemplo aislado de transición a DI marcada con punto y coma, al modo del esquema «; DI» que observamos en (20).

(20) començaron le a gritar diciendole; por que causa âcia tanto ruido;» [p. 37]

Al igual que ocurría con el DD, también es posible que el DR carezca de puntuación aparente, ausencia de puntuación usual en las interrogativas indirectas, caso ilustrado en la segunda parte del ejemplo (21):

(21) añadieron los criados que sus amos venian a todas estas tierras, para vender con secreto mercancias de gran precio, i para en noblecer el arte mercantil, con su generosidad con titulo de asien- [p. 39] tistas de nobleça por su Magestad, preguntaron les de que eran mercaderes: [p. 40]

\section{Discurso mixto en la Olla podrida}

Según la teoría ya presentada de Girón Alconchel, existen diferentes tipos de discurso mixto (DM) a medio camino entre la yuxtaposición del DD y la subordinación del DI.

En primer lugar nos encontramos con el DDS (Discurso Directo Subordinado), consistente en un DD introducido por una conjunción, normalmente la completiva que, o DDL (Discurso Directo Ligado) si la conexión se hace por otros medios como la sustantivación (en cierta manera 
mediante una cita en forma de uso metalingüístico), pero en todo caso faltando puntuación. Ejemplo de DDS sería «que si» en el ejemplo (22), precedido por un DD ordinario aunque sin marca ortográfica, «ya minier», dialecto germánico de Westfalia que en (23) aparece también introducido por la conjunción que en forma de DDS: «que estraque miner». En cambio, «el no» y «el sí» serían formas de DDL (24), que en edición moderna no merecería marcar entre comillas, dado el alto grado de lexicalización que muestran (el mismo DRAE 2001, s.v. sí recoge acepciones en las que la voz aparece marcada gramaticalmente como sustantivo, algo perfectamente extensible a no). El DDL se manifiesta de manera más compleja y sin lexicalizar en (25), donde «toma» es tratado como un sustantivo por la anteposición del artículo indefinido o numeral «un» (se explota de hecho el juego de palabras), y la oración «te daré» es sustantivada por el numeral (en el mismo ejemplo se juega después al calambur «da mas»= damas en un DD introducido por dos puntos).

(22) como si le âblara caldeo; me decia ya minier: buen papel tengo, que pienso que me dice que si: [p. 159]

(23) nunca respondia, que estraque miner. [p. 163]

(24) no lo saben,solo aciertan con el no, i el si, [p. 108]

(25) fuera que las damas no se contentan de un toma, ni de dos te daré, aviendo recibido mucho, aun diran: da mas; i si se les aumenta toda vuestra acienda, diran: da mas; i si aveis puesto en riesgo vuestra vida i onra, aun diran: da mas,como es boca insaciable la suya, siempre masean. [p.224]

En cuanto al Discurso Indirecto Libre o DIL, que en absoluto es un hallazgo moderno (según Cerquiglini 1984 ya se manifiesta en el « ancien français », y Girón Alconchel 1986, 1989, 2000, 2002, 2006 lo localiza en textos medievales españoles como el Mío Cid, Berceo o el Canciller Ayala, y también en clásicos del Siglo de Oro, como Cervantes o Alonso Contreras) es la muestra absoluta o por excelencia de la polifonía textual, pues la voz del enunciador del marco reproductor y del enunciado reproducido se funden. La forma más habitual del DIL es el DIM o Discurso Indirecto Mimético, en el que elementos de mímesis oral (como la presencia de causales de la enunciación) actúan como indicios internos de reproducción del DIL, potenciando aún más la polifonía textual.

Según los trabajos de Girón Alconchel (passim), podemos etiquetar de DIL el DI alargado, que contraviene la característica de brevedad y resumen que posee el DI. Tal alargamiento suele concordar con la supresión de la conjunción subordinada sustantiva que en sucesivas oraciones de DI. 
También sería DIL la presencia de un Discurso Narrado (DN), esto es, la compactación máxima de un $\mathrm{DR}$ en un verbo de lengua seguido de un complemento que indica la unidad de comunicación, como en contó un cuento, que se puede luego ampliar en un DIL. Al igual que de la misma manera es DIL el introducido por un verbo performativo.

De prácticamente todo ello hay muestra en la Olla podrida a la española (1655); de hecho, es más frecuente el DIL o el DI combinado con DIL que el mero DI, sin que por supuesto exista una puntuación especializada para marcar el DIL ${ }^{16}$ más allá de sobre todo la coma introduciendo un miembro más del periodo. Documentamos, pues, DIL en forma de DI alargado con falta de resumen, como en (26), siendo muy frecuente que la extensión del discurso (y por ello la ausencia de resumen) se produzca mediante oraciones de relativo, como en (27).

(26): dixo el dicho Rei Juan, que a ellos, i a los suyos no les faltava otra cosa, por averse dado la mas terrible pançada en un año, que se podia imaginar; i que todos los cinco sentidos estavan satisfechos, el oido oyiendo sutiles tiples femeninos cuyos ecos retumbavan en el alma. El visibo viendo pedaços [p. 216] de cielo estrellado. El olfato ôliendolos. El gusto gustando pechugas de polluelas. El tacto tocandolas, i retocandolas, i aun destocandolas, para mas atiçar al deseo, los quales sentidos allandose opilados, para desensebarlos, piden por postre agrio, pues la comida â sido tan dulce. [p. 217]

(27) fuime a comer con un [p. 120] amigo, dando a entender llegava en tonçes de mi viage, i luego me dixeron como el fuego los avia inquietado, i a todos los abitantes en cierta casa de una dama, que toda se avia quemado, la qual Señora con su madre avian dormido en la mia, desde donde se pasarian por la mañana a otra,que avian alquilado, [p. 121]

También encontramos ejemplos de DI alargado en DIL en el que falta el que subsiguiente a un primer miembro del discurso referido, como en (36) donde hemos introducido entre corchetes el que que hubiera sido necesario:

(28) i asi digo, que ningun filosofo duda en esta era,que el celebro es el istrumento que naturaleça ordenó, para que el ômbre fuese sabio, i prudente; [que] solo conviene esplicar,que condiciones â de tener esta parte, para que se pueda decir estar bien organiçada: i que el ômbre por esta raçon tenga buen ingenio, i abilidad. [p. 87]

16 Recordamos que vamos a marcar el DIL mediante cursiva, conforme suele hacer Girón Alconchel (passim). 
Es muy frecuente asimismo el DIL en forma DIM, sobre todo marcado mediante causales de la enunciación y otros indicios miméticos, como en (29) donde documentamos precisamente la causal de la enunciación introducida por un que equivalente a porque y otro indicio mimético como el clítico doble (le quería acompañarle) en estructuras con posible subida de clíticos (quería acompañarle > le quería acompañar) que podemos tomar como una errata o realmente como un pleonasmo coloquial o vulgar:

(29) [El Doctor García] me decia muchas veces, que el sabia bien, a donde [p. 21] avia de ir despues de su muerte, yo le respondia, que por aquella vez no le queria acompañar le, que a la buelta nos veriamos» (p. 21-22)

En (30) documentamos también DIM con causal de la enunciación, esta vez introducida por un más transparente porque tras el cual se sigue un refrán, a río revuelto, ganancia de pescadores, otro frecuente indicio mimético de habla oral:

(30) Suelen decir (los establistas destos tiempos para engañar, o cubrir el engaño con decente capa) a sus [p. 14] Principes, que es mui conviniente âcer i continuar la guerra, aunque sea rompìndo la paz, i juramento, para bonbear la gente de su reino que es mucha por que aviendo tanta, $i$ estando tan juntos, i apiñados, se daran de coces, dando, principio a guerras civiles, adonde corre riesgo la corona regia i republica, porque arrio buelto ganancia de pescadores [p. 15]

Y de nuevo encontramos DIL/DIM en (31), detectable por la causal de la enunciación introducida por que a la que se suma un marcador del discurso («a lo último») que funciona aquí como indicio oral:

(31) i aunque sea mucho el olor âcen la justicia ediônda, diciendo al paciente, que es necesario prolongar la prision, para que se olvide el delito, que a lo último se le dara un traspie a la justicia, con que goçara de perpetua livertad. [p. 80]

Como último ejemplo de DIL/DIM con causal de la enunciación, destaca el ejemplo (32) en el que se produce un DI dentro de un DI («dicen, que dicen»), otro caso de mise en abyme enunciativa, con una enunciación dentro de una enunciación, dentro de una enunciación..., y enunciadores dentro unos de otros como en una muñeca rusa:

(31) ai cantidad de [p. 103] doncellas en esta ciudad de Munster; unos dicen, que dicen, que lo son de sus madres algunas, i para sus padres otras, que desta suerte, se pueden llamar doncellas con buena conciencia; [p. 104]

Asimismo también encontramos DN ampliado en DIL, como en (32), típico ejemplo de lo que Girón Alconchel ha denominado en diversas 
ocasiones enunciado pluriforme de discurso referido, esto es, aquel en el que aparecen diferentes tipos o instancia de DR, aquí DI, DN y DIL por ser ampliación del $\mathrm{DN}$ «dieron la respuesta», discurso indirecto libre también por la falta de resumen, por los indicios orales como «en gri, en gran i en gro, i en gru», equivalente aquí a la locución actual que si esto, que si lo otro, e incluso por la presencia de causales de enunciación -«que por no tener...»:

(32) preguntaron les de que eran mercaderes: [DI] sin dilacion dieron la respuesta [DN], diciendo, que lo eran en gri,en gra $i$ en gro, i en gru, $i$ que para decir la verdad mas difusa, i no por tantos alambiques, que trocavan cedulas de vida engro,por una fanega de doblas para gastos de guerra, i para sacar almas del pulgatorio, i casar i aun casarse con pobretas, que por no tener, se ivan enpeorando de ropa blanca, i comiendose por averse dado a comer a provetes lisiados movidas de caridad, tanto que en su despensa,âllaran el pelejo vacio, solas las eces i guesos: [p. 40]

Y, por último, incluso el DN ampliado en DIL sin resumen puede adoptar además la forma de un enunciado performativo, otra característica habitual más del DIL, conforme se observa en (33):

(33) en dia, i medio el dicho (volo) de la moça de valde retoça, en los oidos de todas las dichas casadas; las quales, como padeciesen la misma caristia, pidieron [performativo] por una peticion [DN]: que se trocase el decreto, casando quatro ômbres, con una muger; ô que se quitase la pena capital; obligandose ellas, âdar copiosa contribucion a la multiplicacion racional; i que la pena de la adultera se pasase al adultero; quellas no podian con tan gran carga de privacion, siendo destinadas por naturaleça a cargos, i a cargas, para bien i propagacion de su reino, i religion, i para dexar erederos en sus casas; i que por quanto las voladoras, ô aventureras, les qui- [p. 200] tavan sus derechos, i esquilmos, que fuesen todas ellas metidas en una gran casa, âsta que se casasen. [p. 201]

\section{Conclusiones}

A la luz de la Olla podrida a la española (1655), se nos confirma la gradualidad o los límites borrosos del DD y el DI, ya advertida previamente por Girón Alconchel (passim), en el caso del Siglo de Oro. A la vista de la puntuación original, tal porosidad se potencia por el hecho de que tanto DD como DI son marcados por una puntuación (o ausencia de puntuación) similar, aunque con ciertas preferencias (los dos puntos para el DD y la coma para el DI-DIL), hallazgo que ha sido posible por la novedad metodológica de haber trabajado con impresos originales, y no (solo) con ediciones modernas, prueba de que los estudios de sintaxis histórica deberían aliarse 
a los de ortografía histórica. Asimismo, podemos documentar de nuevo (al igual que confirmar) la existencia de una cadena de gramaticalización (no genética o diacrónica) en la gramática del DR del español, de menos a más gramaticalizado o integrado sintácticamente: DD $>$ DM $>$ DI. Pese a que el DIL esté poco gramaticalizado y poco gramatizado (esto es, descrito en los textos gramaticales) según Méndez (2009), en realidad es más frecuente en el texto estudiado que el DI puro.

En este punto, simplemente quería terminar con la reflexión de que quizá la puntuación del Siglo de Oro nos puede parecer ajena o arcaica, pero en realidad no es imposible en la actualidad, de lo cual es prueba un titular del periódico español El País, en el que la mise en abyme de enunciadores (un DD dentro de un DD marcado entre comillas), produce la utilización de una coma tras «era» que marca la transición al segundo DD: «Un etarra arrepentido: "La orden era, vosotros matad todo lo que podáis"» (Madrid, El País, 05/03/2012).

\section{Bibliografía}

\section{Fuentes primarias}

Fernández M., 1647, Instruction espagnole accentuée, Colonia, Por Andrea Bingio [París, BnF, sign. X-2672]

Fernández M., 1655, Olla podrida a la española, En Amberes [=Amsterdam], Por Felipe van Eyck [Madrid, BNE, sign. R/7548] http://bdh.bne.es/bnesearch/detalle/2683745

\section{Fuentes secundarias}

Arellano I., 2005, «Marcos Fernández[:] Olla podrida a la española», Príncipe de Viana, 236, p. 967-968.

Arboleda C., 2011, "Cervantes y el fomento de un nuevo tipo de lector y de lectura. Notas para una Teoría de la lectura reflexiva en el Quijote», Redipe 803, Boletín de la Red Iberoamericana de Pedagogía http://rediberoamericanadepedagogia.com/ index.php/component/content/article?id=45

Catach N., 1996, La ponctuation ( $2^{a}$ ed. corr.), Paris, Presses Universitaires de la France. Cerquiglini B., 1984, «Le style indirect libre et la modernité», Langages, 73, p. 7-16.

Díez Fernández I., 2008, «[Reseña de:] Fidel SEBASTIÁN MEDIAVILLA: Puntuación, humanismo e imprenta en el Siglo de Oro, Vigo, Academia del Hispanismo, 2007, 152 p.». Dicenda, 26, p. 384-387.

Girón Alconchel J. L., 1985, «La "escritura del habla" y el discurso indirecto libre en español», Archivo de Filología Aragonesa, XXXVI-XXXVII, p. 173-204.

Girón Alconchel J. L., 1986, «El discurso directo como modelo semiótico de la lengua medieval», Investigaciones semióticas, vol. I, Madrid, CSIC, p. 233-256. 
Girón Alconchel J. L., 1989, Las formas del discurso referido en el Cantar de Mio Cid, Madrid, RAE.

Girón Alconchel J. L., 1996, «Las gramáticas del español y el español de las gramáticas en el Siglo de Oro», Boletín de la Real Academia Española, LXXV, p. 285-308.

Girón Alconchel J.L., 2000, «Sintaxis y discurso en el español del Siglo de Oro (Contribución a la historia del discurso indirecto libre)», Voz y Letra, XI:1, p. 93-113.

Girón Alconchel J.L., 2002, «Discurso indirecto libre y autobiografía en la Vida del Capitán Contreras», en Carmen Saralegui y Manuel Casado (eds.), Pulchre, bene, recte. Estudios en homenaje al Prof. Fernando González Ollé, Pamplona, EUNSA, p. 625-638.

Girón Alconchel J.L., 2006, «Sobre la gramaticalización del discurso referido», en Concepción Company Company (ed.), El español en América. Diatopía, diacronía e historiografía. Homenaje a José G. Moreno de Alba, México, UNAM, p. 395-406.

Girón Alconchel J. L., 2008, «Tradiciones discursivas y gramaticalización del discurso referido en el Rimado de Palacio y las Crónicas del Canciller Ayala», en Johannes Kabatek (ed.), Sintaxis histórica del español y cambio lingüístico, Madrid/ Frankfurt am Main, Iberoamericana/Vervuert, p. 173-196.

Greg Walter W., 1950-1951, «The Rationale of Copy-Text», Studies in Bibliography, 3: 20-37 http://etext.lib.virginia.edu/bsuva/sb

Herrero Ruiz de Loizaga F.J., 2005, Sintaxis histórica de la oración compuesta. Madrid, Gredos.

Kristeva J., 1969, Sèmiotiké: recherches pour une sémanalyse, Paris, Editions du Seuil.

López Navia S., 2006, «Las claves de la metaficción en el «Quijote»una revisión», Oppidum: cuadernos de investigación, 2, p. 169-186

Maldonado González C., 1991, Discurso directo y discurso indirecto, Madrid, Taurus. Maldonado González C., 1999, «Discurso directo y discurso indirecto», en Ignacio Bosque/Violeta Demonte (eds.), Gramática descriptiva de la lengua española, vol. 3, Madrid, Espasa-Calpe, p. 3549-3595.

Méndez, Elena, 2009, "Los enunciados del discurso referido y la gramática», en M. ${ }^{a}$ Victoria Camacho Taboada et al., Estudios de lengua española: descripción, variación y uso, Madrid/Frankfurt am Main, Iberoamericana/Vervuert, p. 483-517.

Pagnoni B., Fernando G., 2011, «Metaficción como artificio y teorías del humor. Del barroco a la postmodernidad», Anagnórisis: Revista de Investigación Teatral,3, p. 54-75. http://www.anagnorisis.es/

RAE, 2001, Diccionario de la lengua española, Madrid, Espasa-Calpe = DRAE.

Sáez Rivera D.M., 2005, «La Olla podrida a la española (1655) o los presuntos entretenimientos de un maestro de lenguas del siglo XVII», en $\mathrm{M}^{\mathrm{a}}$ Carmen Cazorla Vivas et al., Estudios de historia de la lengua e historiografía lingüística: Actas del III Congreso Nacional de la AJIHLE (Jaén, 27, 28 y 29 de marzo de 2003), Madrid, AJIHLE, p. 457-467.

Sáez Rivera D.M., 2008a, La lengua de las gramáticas y métodos de español como lengua extranjera en Europa (1640-1726), Madrid, Servicio de Publicaciones de la Universidad Complutense. http://www.ucm.es/BUCM/tesis/fll/ucm-t30253.pdf 
Sáez Rivera D.M., 2008b, «Marcos Fernández: “Capítulo y explicación de la palabra hidalgo o hidalga", en Olla podrida a la española... (1655)», Anales Cervantinos, XL, p. 283-310. http://analescervantinos.revistas.csic.es/index.php/ analescervantinos/article/view/48/48

Sáez Rivera D. M., 2009, «La edición de textos con ortografía idiosincrásica: el caso de Marcos Fernández, gramático y ortógrafo del siglo XVII», Philologia Hispalensis, XXIII:3: 117-142. http://institucional.us.es/revistas/philologia/23/07\%20Saez.pdf

Sáez Rivera D.M., 2010, «Marcos Fernández y su versión española de los diálogos latino-franceses de Philippe Garnier (Amsterdam, 1656; Estrasburgo, 1659)», Recherches, 5, p. 173-201.

Sánchez Laílla L., 2001, "A propósito de la puntuación de El Criticón», Criticón, 83, p. 163-176.

Santiago R., 1998, "Apuntes para la historia de la puntuación en los siglos XVI y XVII», en José M. Blecua et al., Estudios de grafemática en el dominio hispánico, Salamanca, Ediciones Universidad de Salamanca, p. 243-280.

Sebastián Mediavilla F., (2000): La puntuación en el Siglo de Oro: teoría y práctica, Barcelona, Universitat Autònoma de Barcelona. http://www.tdx.cat/handle/1080 3/4855; jsessionid=2F8173E8ABE611FEDED8CD0CEF5729D2.tdx2

Sebastián Mediavilla F., 2002, La puntuación en los siglos XVI y XVII, Bellaterra, Servei de Publicacions, Universitat Autònoma de Barcelona.

Sebastián Mediavilla F. , 2007, Puntuación, humanismo e imprenta en el Siglo de Oro, Vigo, Academia del Hispanismo.

Sebastián Mediavilla F., 2008, La puntuación del Quijote (1605-1615), Vigo, Academia del Hispanismo.

Sebastián Mediavilla F., 2010, Fray Luis y Santa Teresa, imprentas y editores (cuestiones de ortografía y puntuación), Vigo, Academia del Hispanismo.

Valdés, R., 2006, «Rasgos distintivos y corpus de la sátira menipea española en su Siglo de Oro», en Carlos Vaíllo y Ramón Valdés (eds.), Estudios sobre la sátira española en el Siglo de Oro, Madrid, Castalia, p. 179-207

Valdés, R., 2008, «La historia en la sátira menipea: de Séneca y Luciano a Alfonso de Valdés y los modelos humanistas», en Ana Vian Herrero/Consolación Baranda Leturio (eds.), Letras humanas y conflictos del saber: la filología como instrumento a través de las edades, Madrid, Instituto Universitario Menéndez Pidal/Universidad Complutense de Madrid, p. 127-181.

Vaíllo, C., 2006, «La sátira de un expatriado español: la Olla podrida (1655), de Marcos Fernández», en Carlos Vaíllo y Ramón Valdés (eds.), Estudios sobre la sátira española en el Siglo de Oro, Madrid, Castalia, p. 151-178. 